\title{
Identification of genetic association between cardiorespiratory fitness and the trainability genes in childhood acute lymphoblastic leukemia survivors
}

Maxime Caru ${ }^{1,2,3^{*}}$ D , Kateryna Petrykey ${ }^{3,4}$, Simon Drouin $^{3}$, Patrick Beaulieu ${ }^{3}$, Pascal St-Onge ${ }^{3}$, Valérie Lemay ${ }^{1,3}$, Laurence Bertout $^{3}$, Caroline Laverdiere ${ }^{3,5}$, Gregor Andelfinger ${ }^{3,5}$, Maja Krajinovic ${ }^{3,4,5}$, Daniel Sinnett ${ }^{3,5}$ and Daniel Curnier ${ }^{1,3}$

\begin{abstract}
Background: The progress of treatments of childhood acute lymphoblastic leukemia (ALL) has made it possible to reach a survival rate superior to $80 \%$. However, the treatments lead to several long-term adverse effects, including cardiac toxicity. Although studies have reported associations between genetic variants and cardiorespiratory fitness, none has been performed on childhood ALL survivors.

Methods: We performed whole-exome sequencing in 239 childhood ALL survivors from the PETALE cohort. Germline variants (both common and rare) in selected set of genes $(N=238)$ were analyzed for an association with cardiorespiratory fitness.
\end{abstract}

Results: Our results showed that the common variant in the $\Pi \mathrm{N}$ gene was significantly associated with a low cardiorespiratory fitness level $(p=0.0005)$ and that the LEPR, IGFBPI and ENO3 genes were significantly associated with a low cardiorespiratory fitness level in female survivors $(p \leq 0.002)$. Also, we detected an association between the low cardiorespiratory fitness level in participants that were stratified to the "high risk" prognostic group and functionally predicted rare variants in the SLC22A16 gene ( $p=0.001)$. Positive associations between cardiorespiratory fitness level and trainability genes were mainly observed in females.

Conclusions: For the first time, we observed that low cardiorespiratory fitness in childhood ALL survivors can be associated with variants in genes related to subjects' trainability. These findings could allow better childhood ALL patient follow-up tailored to their genetic profile and cardiorespiratory fitness, which could help reduce at least some of the burden of long-term adverse effects of treatments.

Keywords: Acute lymphoblastic leukemia, Pediatric cancer survivorship, Genetic association study, Cardiorespiratory fitness, Cardiovascular health, Trainability genes

\footnotetext{
* Correspondence: maxime.caru@umontreal.ca

'Laboratoire de Physiopathologie de l'EXercice (LPEX), École de Kinésiologie

et des Sciences de l'Activité physique, Faculté de Médecine, Université de Montréal, CEPSUM, 2100, boulevard Édouard Montpetit, Montréal, QC H3C 3J7, Canada

${ }^{2}$ Department of psychology, Laboratoire EA 4430 - Clinique Psychanalyse

Developpement (CliPsyD), University of Paris Nanterre, Nanterre,

Ile-de-France, France

Full list of author information is available at the end of the article
}

(c) The Author(s). 2019 Open Access This article is distributed under the terms of the Creative Commons Attribution 4.0 International License (http://creativecommons.org/licenses/by/4.0/), which permits unrestricted use, distribution, and reproduction in any medium, provided you give appropriate credit to the original author(s) and the source, provide a link to the Creative Commons license, and indicate if changes were made. The Creative Commons Public Domain Dedication waiver (http://creativecommons.org/publicdomain/zero/1.0/) applies to the data made available in this article, unless otherwise stated. 


\section{Background}

Childhood acute lymphoblastic leukemia (ALL) is the most common pediatric cancer, representing about 30\% of all childhood malignancies. Over the past four decades, the progress in treatments for childhood ALL has made it possible to achieve a five-year survival rate over $80 \%$ [1].

However, the aggressive treatments regimen often lead to several long-term adverse effects, including cardiac toxicity and cardiovascular issues in survivors [2]. Physical activity has an important role in the prevention of cardiovascular diseases and in the management of metabolic disorders. A good cardiorespiratory fitness level in childhood ALL survivors has shown a significant positive impact on mental health, quality of life, bone strength and mortality [3-6]. It has been shown in healthy and untrained populations that there is a great inter-individual variability in subjects' capacity to improve their cardiac profile in response to regular exercise [7]. This can partly be explained by genetic variations between subjects, which can ultimately have an influence on their trainability [8]. Studies on healthy subjects and athletes have reported associations between genetic variants and changes in muscle strength $[9,10]$ and cardiorespiratory fitness in response to exercise [11]. It is essential to improve our knowledge of genetic determinants of trainability in childhood ALL survivors given that anticancer drugs, such as anthracyclines, can modify gene expression [12] and induce an impairment of cardiac function [13].

In this study, we investigated candidate genes linked to health-related fitness and performance and their association to high and low cardiorespiratory fitness levels in a cohort of childhood ALL survivors. Such genetic biomarkers will be important in the post-treatment follow-up of childhood ALL survivors by allowing personalized cardiorespiratory fitness risk management interventions.

\section{Methods}

\section{Study population}

All 239 participating childhood ALL survivors were diagnosed between 1987 and 2010 and treated according to DFCI-ALL 87-01 to $05-01$ protocols [14] at Sainte-Justine University Health Center (SJUHC), Montreal (Quebec), Canada. The participants were recruited in the context of the PETALE study, a multidisciplinary research project with the goal to identify and to comprehensively characterize associated predictive biomarkers of long-term treatment related complications in childhood ALL survivors [15]. These participants had no history of refractory or recurrent disease and did not receive a hematopoietic stem cell transplant. These participants were almost exclusively of French Canadian descent (>95\%), with predominantly European ancestry
[15]. In the current study, we restricted participants to those that were less than 19 years old at diagnosis. Subjects who have suffered from congenital bone disease or who received osteotoxic drugs for non-ALL disease were excluded. Written informed consent was obtained from every patient or parent/legal guardian. The study was conducted in accordance with the Declaration of Helsinki and the protocol was approved by the Ethics Review Committee of SJUHC.

\section{Measurements \\ Cardiopulmonary exercise test}

The McMaster incremental cycle protocol [16] was performed on an electromagnetic cycle ergometer (Ergoline, ER900, Bitz, Germany). The test consisted of a standard incremental procedure at a pedaling cadence of 50-70 rpm starting at $25 \mathrm{~W}$, increasing the load by $25 \mathrm{~W}$ or 50 W (depending on the height and sex of the subject) every $2 \mathrm{~min}$. At the end of the test, an active rest period at $25 \mathrm{~W}$ for $3 \mathrm{~min}$ was followed by a passive rest period of $3 \mathrm{~min}$. All subjects were monitored continuously during the test with twelve-lead electrocardiograms (CASE Exercise Testing, GE Marquette, Milwaukee, WI, USA). Blood pressure was measured every $2 \mathrm{~min}$ (Tango M2, SunTech Medical, Morrisville, NC, USA). Both the cardiologist and the exercise physiologist determined whether the subjects reached two out of three of the following criteria to validate their $\dot{\mathrm{V}} \mathrm{O}_{2}$ peak: a respiratory exchange ratio value $>1.15$, OMNI $>7$, and $\mathrm{HR}_{\max } \geq$ $85 \%$ of the predicted value [17].

\section{Predicted maximum oxygen uptake}

The maximum oxygen uptake (ن்2 peak) was measured during the McMaster incremental cycle protocol with a breath-by-breath system (Oxycon Pro, Viasys Healthcare, Germany) calibrated prior to each test. Breath-by-breath data were averaged in $20 \mathrm{~s}$ intervals. For subjects $\geq 18$ years old, predicted $\dot{\mathrm{V}} \mathrm{O}_{2}$ peak was calculated using equations published by Wasserman and Hansen [18, 19], depending on age, sex, weight and height. For subjects < 18 years old the Cooper formula $[19,20]$ was used to predict $\dot{\mathrm{V}} \mathrm{O}_{2}$ peak. An adjustment for overweight subjects was achieved with an addition of $6 \mathrm{~mL} \cdot \mathrm{kg}^{-1} \cdot \mathrm{min}^{-1}$ for each $\mathrm{kg}$ of weight exceeding their normal weight [19] as calculated based on the 50th percentile of the World Health Organization body mass index charts for children [21].

\section{Cardiorespiratory fitness level}

The percentage of cardiorespiratory fitness is the ratio between measured and predicted $\dot{\mathrm{V}} \mathrm{O}_{2}$ peak: $\left[\left(\dot{\mathrm{V}} \mathrm{O}_{2}\right.\right.$ peak measured $/ \dot{\mathrm{V}} \mathrm{O}_{2}$ peak predicted $) \times 100$. A higher per- 
centage of $\dot{\mathrm{V}} \mathrm{O}_{2}$ peak thus corresponded to a higher level of cardiorespiratory fitness.

\section{Whole Exome Sequencing (WES)}

We performed whole-exome sequencing (WES) on a total of 239 participants. Whole exomes were captured in solution with Agilent's SureSelect Human All Exon $50 \mathrm{Mb}$ kits. Sequencing data (mean coverage $\sim 40 \mathrm{X}$ ) were generated on the SOLiD 4.0 (ThermoFisher Scientific) or Illumina HiSeq 2500 platform (mean coverage = 113.1X) (SJUHC and Génome Québec Integrated Centre for Pediatric Clinical Genomic platform). Reads were aligned on the Hg19 reference genome. PCR duplicates are removed using Picard [22]. Variant quality score recalibration was performed using the HaplotypeCaller implemented in Genome Analysis ToolKit (GATK) [23] and QC Failure reads was removed. Generic alignment format SAMtools was used to create pileup files from cleaned BAM files [24]. Rare and common variants with a predicted functional impact on protein were identified by functional annotation from ANNOVAR [25]. Variants considered as potentially damaging as per SIFT $(<0.1)$ [26] and Polyphen2 $(\geq 0.85)$ [27]. Minor allele frequencies (MAF) were derived from the 1000 Genomes (European population) [28] and the NHLBI GO Exome Sequencing Project (European population, ESP) [29].

\section{Power analysis}

Quanto software (version 1.2.4) [30] was used to compute a power analysis at $80 \%$. For common variants (MAF of 5-30\%), the power analysis revealed that the odds ratio ranged from 3 to 9 (depending on the outcome analyzed). The lowest odds ratio for rare variants (MAF of 0.01) that could be detected with a given sample size, was 26 . The Bonferroni correction was used for the number of SNPs or genes tested.

\section{Association studies and statistical analysis}

A list of candidate genes was generated through a review of the literature. The genes expected to influence the outcome associated with health-related fitness and performance (i.e. cardiorespiratory endurance, anaerobic, trainability, exercise hemodynamic, exercise intolerance and muscular strength) were targeted [31-33]. Additional candidate genes were selected via a Gene Oncology Enrichment Analysis and Visualization Tool (Gorilla) [34]. A total of 238 candidate genes (134 common variants and 1225 rare variants) were chosen (Additional file 1: Tables S1 and S2). Variants that did not conform to the Hardy-Weinberg equilibrium ( $p=$ 0.001 ) and/or with a total missing rate $>20 \%$ were excluded prior to analyses. Variants with a high linkage disequilibrium were excluded $\left(r^{2}>0.8\right)$.
Genetic association analyses between common genetic variants and cardiorespiratory fitness level were performed using allelic ratio implemented in PLINK v.1.07 [35]. The Benjamini and Hochberg method (FDR) was used to correct for multiple testing for candidate genes and variants with a FDR less than 0.10 were kept for further analyses [36-38]. Analyses were done by chi-square and Fisher's exact test, as was applicable. Analyses were performed in all 239 subjects and upon stratification by sex, age at visit, time from the end of the treatment and prognostic risk group (i.e. standard risk (SR), high risk with and without cardio-protective agent dexrazoxane (HR and HR + DEX)) [14]. The cumulative doxorubicin dose for the SR group was $60 \mathrm{mg} / \mathrm{m}^{2}, 300 \mathrm{mg} / \mathrm{m}^{2}$ for the $\mathrm{HR}+\mathrm{DEX}$ group and either $360 \mathrm{mg} / \mathrm{m}^{2}$ (DFCI-ALL protocols $85-01, \quad 87-01$ and $91-01)$ or $300 \mathrm{mg} / \mathrm{m}^{2}$ (DFCI-ALL protocols 95-01) for the HR group. For rare variants associations, we used the SKAT-O test (Optimal Sequence Kernel Association Test) implemented in $\mathrm{R}$ v.3.2.1 [37, 39]. To test the individual contribution, we used the collapsing approach with the iterative exclusion of individual variants for rare variants associations. Adjustment for multiple testing was performed by bootstrap FDR method [40] implemented in QVALUE [41]. Genetic variants associated with cardiorespiratory fitness were analyzed using logistic regression including four covariables: age at visit, sex, cumulative doxorubicin dose and time from the end of the treatment.

For clinical characteristics, a two-tailed Student t-test with a significance level of $5 \%$ was performed. A Chi-square test with a threshold of $5 \%$ was used to compare two percentages. A Fisher exact test was used when the conditions for applying a Chi-square test were not met. All variables were reported as mean \pm standard deviation (SD) or as percentage. Cardiorespiratory fitness data were verified for normal distribution using the Shapiro-Wilk test. All analyses were performed using SPSS version 24.0 [42].

\section{Results}

A total of 239 childhood ALL survivors were included in our analyses (Table 1). Participants were divided in two groups according to their median predicted $\dot{\mathrm{V}} \mathrm{O}_{2}$ peak. The first group opposed above and below the median of cardiorespiratory fitness level of the childhood ALL survivors ( $<83.8 \%$ vs $\geq 83.8 \%$ ) (Table 2 ), whereas the second group opposed the two extremes at least two standard deviations away from the median $(\leq 48.3 \%$ vs $\geq 125.6 \%)$ (Additional file 1: Table S3).

The common variants analyses are presented in Table 3 (also see Additional file 1: Table S4). The carriers of the TTN minor allele were overrepresented among survivors with a cardiorespiratory fitness level $<83.8 \%$. The major 
Table 1 Clinical characteristics of acute lymphoblastic leukemia survivors

\begin{tabular}{|c|c|c|c|}
\hline & Childhood ALL survivors & Females & Males \\
\hline Total & 239 & 120 & 119 \\
\hline Age at visit (y) & $21.5 \pm 6.1$ & $21.5 \pm 6.3$ & $21.6 \pm 6.0$ \\
\hline Age at cancer diagnosis (y) & $6.3 \pm 4.6$ & $6.2 \pm 4.4$ & $6.4 \pm 4.7$ \\
\hline Time from the end of the treatment $(\mathrm{y})$ & $13.0 \pm 5.0$ & $13.0 \pm 5.3$ & $12.9 \pm 4.8$ \\
\hline Weight (kg) & $66.8 \pm 16.4$ & $63.7 \pm 16.6$ & $70.0 \pm 15.7$ \\
\hline Height (cm) & $166.9 \pm 10.0$ & $160.3 \pm 6.7$ & $171.5 \pm 9.6$ \\
\hline$\dot{\mathrm{V}} \mathrm{O}_{2}$ peak $\left(\mathrm{mL} \cdot \mathrm{kg}^{-1} \cdot \mathrm{min}^{-1}\right)$ & $32.6 \pm 8.4$ & $27.6 \pm 6.5$ & $36.9 \pm 7.4^{*}$ \\
\hline Power at $\dot{\mathrm{V}} \mathrm{O}_{2}$ peak $(\mathrm{W})$ & $174.7 \pm 55.3$ & $133.5 \pm 28.9$ & $213.8 \pm 45.0^{*}$ \\
\hline$\dot{\mathrm{V}} \mathrm{O}_{2}$ peak predicted $(\%)$ & $85.7 \pm 17.1$ & $86.8 \pm 18.3^{*}$ & $83.2 \pm 15.4$ \\
\hline Physical activity (min) & $27.8 \pm 29.4$ & $24.9 \pm 30.3$ & $30.5 \pm 28.4^{*}$ \\
\hline $\operatorname{DOX}\left(\mathrm{mg} / \mathrm{m}^{2}\right)$ & $182.8 \pm 119.7$ & $183.4 \pm 121.9$ & $182.2 \pm 117.9$ \\
\hline $\operatorname{DEX}\left(\mathrm{mg} / \mathrm{m}^{2}\right)$ & $2781.0 \pm 440.0$ & $2828.8 \pm 374.4$ & $2731.8 \pm 499.4$ \\
\hline
\end{tabular}

ALL acute lymphoblastic leukemia, DOX cumulative dose of doxorubicin, DEX cumulative dose of dexrazoxane. Physical activity variable represents minutes per day of moderate or intense leisure physical activities. Data are expressed as percentage or as means \pm SD. ${ }^{*} p<0.05$, Females versus Males

allele in other genes (LEPR, IGFBP1 and ENO3) had, in contrast, a protective role and were represented less frequently among female survivors who had cardiorespiratory fitness level $<83.8 \%$. Significant genetic variants were further analyzed in logistic regression (Table 3 and Additional file 1: Table S4) in which the effect of genetic variant is adjusted for age at visit, sex, cumulative doxorubicin dose and time from end of the treatment and no significant confounding factors were observed in these associations. The analysis of functionally predicted rare variants detected an association (with FDR $<10 \%$ ) between the low cardiorespiratory fitness level and rare variants enrichment in the SLC22A16 gene for the HR group $(p=0.001)$ (Additional file 1: Table S5). Our

Table 2 Clinical characteristics of acute lymphoblastic leukemia survivors according to their cardiorespiratory fitness level

\begin{tabular}{|c|c|c|}
\hline & \multicolumn{2}{|l|}{ Group 1} \\
\hline & $<83.8 \%$ & $\geq 83.8 \%$ \\
\hline Total & 119 & 120 \\
\hline Gender (Females / Males) & $54 / 65$ & $66 / 54$ \\
\hline Age at visit (y) & $21.6 \pm 5.9$ & $21.5 \pm 6.4$ \\
\hline Age at cancer diagnosis (y) & $6.2 \pm 4.8$ & $6.3 \pm 4.4$ \\
\hline Time from the end of the treatment $(y)$ & $13.1 \pm 5.1$ & $12.8 \pm 5.0$ \\
\hline Weight (kg) & $67.4 \pm 18.1$ & $66.2 \pm 14.6$ \\
\hline Height (cm) & $166.1 \pm 11.5$ & $165.6 \pm 8.3$ \\
\hline$\dot{\mathrm{v}} \mathrm{O}_{2}$ peak $\left(\mathrm{mL} \cdot \mathrm{kg}^{-1} \cdot \mathrm{min}^{-1}\right)$ & $28.5 \pm 6.2$ & $35.8 \pm 8.6^{*}$ \\
\hline Power at $\dot{\mathrm{V}} \mathrm{O}_{2}$ peak $(\mathrm{W})$ & $162.6 \pm 55.2$ & $185.6 \pm 53.3^{*}$ \\
\hline$\dot{\mathrm{V}} \mathrm{O}_{2}$ peak predicted $(\%)$ & $71.9 \pm 10.0$ & $98.0 \pm 11.7^{*}$ \\
\hline Physical activity (min) & $22.4 \pm 29.6$ & $32.9 \pm 28.5^{*}$ \\
\hline
\end{tabular}

Physical activity variable represents minutes per day of moderate or intense leisure physical activities. Data are expressed as percentages or as means \pm SD. ${ }^{*} p<.05$ analyses of rare variants showed a significant association with a low cardiorespiratory fitness in the HR group without the cardio-protective agent dexrazoxane. No other association with the appropriate FDR threshold was shown in our analysis of rare variants. In order to identify the individual contributions to the observed association signal, we explored different variant combinations with the collapsing approach. The significant signal came from the SLC22A16 gene where three variants (rs41288594, rs61729086, rs146329765) were contributing to the signal (Additional file 1: Table S5). Our analyses reported the individual contribution of variant rs61729086 but showed no individual contributions of variants rs41288594 and rs146329765. The significant genetic variant was further analyzed in a logistic regression (Additional file 1: Table S5). Analyses revealed that there was no significant effect of co-variables in the multivariate model due to the confounding effects of other covariates and the small sample size of the low frequency genetic variant.

\section{Discussion}

This study was the first to assess genetic determinants of the cardiorespiratory fitness level in childhood ALL survivors. We observed that a low cardiorespiratory fitness was associated with genes primarily related to survivors' trainability, particularly with common variants in the TTN, LEPR, IGFBPI and ENO3 genes and with a rare variant in the SLC22A16 gene. This was particularly obvious among female survivors.

The involvement of TTN and LEPR, two cardiac-related genes were associated with a decrease of cardiorespiratory fitness in survivors. Our findings showed that the common variant rs6723526 in TTN was associated to survivors with cardiorespiratory fitness level $<83.8 \%$. 
Table 3 Significant genetic associations between cardiorespiratory fitness and common variants

\begin{tabular}{|c|c|c|c|c|c|c|c|c|c|c|c|c|}
\hline & \multirow[t]{3}{*}{ Gene } & \multirow[t]{3}{*}{ SNPs ID } & \multicolumn{2}{|c|}{ Minor Alleles } & \multicolumn{2}{|c|}{ Major Alleles } & \multirow[t]{3}{*}{$p$-value } & \multirow[t]{3}{*}{ FDR } & \multirow[t]{3}{*}{ MAF } & \multirow{3}{*}{$\begin{array}{l}\text { OR }(95 \% \\
\mathrm{Cl})\end{array}$} & \multirow[t]{3}{*}{$p$-value } & \multirow{3}{*}{$\begin{array}{l}\text { OR }(95 \% \\
(\mathrm{Cl})^{*}\end{array}$} \\
\hline & & & Affected & Unaffected & Affected & Unaffected & & & & & & \\
\hline & & & N (\%) & N (\%) & N (\%) & N (\%) & & & & & & \\
\hline $\begin{array}{l}\text { Survivors }<83.8 \% \\
\text { predicted } \dot{V} \text { O2 peak }\end{array}$ & TTN & rs6723526 & $33(14.47)$ & 195 (85.53) & $9(4.55)$ & 189 (95.45) & 0.0005 & 0.04 & 0.1 & $\begin{array}{l}3.55 \\
(1.66-7.63)\end{array}$ & 0.0006 & $\begin{array}{l}4.47 \\
(1.89-10.53)\end{array}$ \\
\hline \multirow{3}{*}{$\begin{array}{l}\text { Female survivors } \\
<83.8 \% \text { predicted } \\
\dot{V} \text { O2 peak }\end{array}$} & LEPR & rs1137100 & $22(17.19)$ & $106(82.81)$ & $34(37.78)$ & $56(62.22)$ & 0.0008 & 0.03 & 0.25 & $\begin{array}{l}0.34 \\
(0.18-0.64)\end{array}$ & 0.003 & $\begin{array}{l}0.33 \\
(0.15-0.68)\end{array}$ \\
\hline & |GFBP1 & rs4619 & $43(33.59)$ & $85(66.41)$ & $51(56.67)$ & $39(43.33)$ & 0.0008 & 0.03 & 0.42 & $\begin{array}{l}0.39 \\
(0.22-0.67)\end{array}$ & 0.01 & $\begin{array}{l}0.46 \\
(0.24-0.86)\end{array}$ \\
\hline & ENO3 & rs238239 & $41(32.54)$ & 85 (67.46) & $46(53.49)$ & $40(46.51)$ & 0.002 & 0.05 & 0.4 & $\begin{array}{l}0.42 \\
(0.24-0.74)\end{array}$ & 0.005 & $\begin{array}{l}0.34 \\
(0.16-0.73)\end{array}$ \\
\hline
\end{tabular}

Threshold of FDR (false discovery rate) was 0.10 . Affected were survivors who have a cardiorespiratory fitness level $\geq 83.8 \%$ and unaffected were survivors who have a cardiorespiratory fitness level $<83.8 \%$. Results from genetic association were presented using allelic model, while results from adjusted logistic regression was presented using the genotypic model (i.e. additive)

SNPs single-nucleotide polymorphisms, MAF Minor allele frequency, OR Odds Ratio

*Logistic regression adjusted for age at visit, sex, cumulative doxorubicin dose and time from end of the treatment

TTN, which encodes the protein titin, one of the most abundant proteins in the human striated muscle myofilament [43] and plays an essential role in skeletal and cardiac muscle [44]. The HERITAGE family study demonstrated a similar influence of the TTN gene in regards to cardiac function during endurance training [45]. We also found that the common variant rs1137100 in the LEPR gene encoding the leptin receptor involved in body weight regulation [46], insulin resistance [47] and physiological adaptation response to exercise [48], was associated with a cardiorespiratory fitness level $<83.8 \%$ and $\leq 48.3 \%$ in female survivors. The LEPR gene had been reported by the HERITAGE study as associated with a lower $\dot{\mathrm{V}} \mathrm{O}_{2}$ max training response [49] and was also associated with significantly lower physical activity levels in young children in another report [50]. Thus, the TTN and the LEPR genes are respectively associated with cardiac function during endurance training and a lower $\dot{\mathrm{V}} \mathrm{O}_{2}$ max training response.

Another gene linked to insulin resistance is IGFBP1. This gene is also associated with lower cardiorespiratory fitness in female survivors. Indeed, we found that the common variant rs4619 in IGFBP1 was associated with a cardiorespiratory fitness level $<83.8 \%$ and $\leq 48.3 \%$, especially in female survivors. This gene is a member of the insulin-like growth factor binding protein family which plays an important role in cell migration and metabolic processes, influencing cardiorespiratory fitness level due to its role in energy metabolism [51]. It has been reported that while there is no significant change in IGFBP1 levels in response to exercises with high resistance [52], changes are observed in response to exercises that are short in duration [53].

Similarly to the positive association between the expression of the IGFBP1 gene and physical inactivity [54], the enolase 3 (ENO3) gene is positively associated with exercise intolerance [55]. The ENO3 gene is especially important because of its role in muscle development and regeneration [56]. It encodes $\beta$-enolase and is mainly expressed in adult striated muscle (i.e. skeletal and cardiac muscle) $[57,58]$. It has been found that the absolute cellular level of enolase activity is higher in skeletal muscle than in other tissues (e.g., liver, kidney, spleen and neural tissues) [59] due to the heavy metabolic requirement of skeletal muscle [55]. Our findings showed that the common variant rs238239 in the ENO3 gene was associated with a cardiorespiratory fitness level $<83.8 \%$ in female survivors. LEPR, IGFBP1 and ENO3 genes were found to be only significantly associated with a lower cardiorespiratory fitness in female survivors. As discussed previously, these genes play important roles in energy metabolism, body weight regulation and muscle development and regeneration $[46,51,56]$. Female survivors showed a greater impairment of total daily energy expenditure after treatments with anthracyclines [2]. Indeed, it is reported that in ALL survivors, cardiorespiratory levels are significantly lower in comparison to a similarly aged non-cancer population, especially in female survivors [60]. Many studies have reported a deterioration of the cardiorespiratory fitness in female survivors [60-63], which is consistent with our genetic association.

The absence of results in the common variants analysis with stratification by prognostic risk group (i.e. SR, HR and HR + DEX) was unexpected and could be due to lack of power. Indeed, several studies have shown genetic contributions to cardiac toxicity induced by higher cumulative dose of anthracyclines in pediatric cancer patients [64-66]. These findings confirmed that the doxorubicin dose can be an important risk factor $[65,67]$ which can affect the cancer subjects' trainability [68] and their cardiovascular response [69-71]. It has been shown that the SLC22A16 gene could contribute to variations in the doxorubicin pharmacokinetics, resulting in a 
possible higher incidence of adverse effects [72]. SLC22A16 also plays a key role in mitochondrial fat oxidation by transporting carnitine, which is important during exercise [73]. Previous studies have shown that its supplementation of carnitine has the potential to improve $\beta$-oxidation during exercise in order to improve performance by making ATP available for mechanical work [74-77]. In this study, we found that a low cardiorespiratory fitness was detected in association with the presence of rare variants in the SLC22A16 gene. Our findings revealed that there was no significant effect of co-variables in the multivariate model due to the confounding effects of other covariates. A previous study reported that the $S L C 22 A 16$ gene was associated with the doxorubicin dose in female cancer patients [78]. This could explain that for survivors in our HR group, the SLC22A16 gene was negatively associated with cardiorespiratory fitness.

It should be noted that our statistical power is limited by the relatively small sample size $(n=239)$. The strengths of our study is the analysis of French Canadian population because it is characterized by its homogeneity, not only at the genetic level but also in terms of lifestyle [15]. Moreover, no significant differences between the frequency of common variant alleles between French-Canadian and other populations of European descent have been reported [79].

\section{Conclusion}

In conclusion, this study provided evidence of genetic predispositions to low cardiorespiratory fitness level in childhood ALL survivors. However, further replication analysis and confirmation of these findings are needed. The identification of novel genetic biomarkers associated with lower cardiorespiratory fitness potential will help reduce the burden of cardiorespiratory long-term adverse effects. As a matter of fact, it will enable the development of personalized follow-ups and preventive strategies for childhood ALL survivors to mitigate this vulnerability.

\section{Additional file}

Additional file 1: Table S1. List of common candidate genes included in the study. Table S2. List of rare candidate genes included in the study. Table S3. Clinical characteristics of acute lymphoblastic leukemia survivors with a very low or very high cardiorespiratory fitness level. Table S4. Significant genetic associations between very low or very high cardiorespiratory fitness and common variants. Table S5. Significant genetic associations between cardiorespiratory fitness and rare variants. (DOCX $101 \mathrm{~kb}$ )

\section{Abbreviations}

ALL: Acute lymphoblastic leukemia; FDR: False discovery rate; HR: High risk without cardio-protective agent dexrazoxane; HR+DEX: High risk with cardioprotective agent dexrazoxane; MAF: Minor allele frequency; PETALE: Prévenir les effets tardifs des traitements de la leucémie aigüe lymphoblastique chez I'enfant; SNP: Single-nucleotide polymorphism; SR: Standard risk; $\dot{V}$

$\mathrm{O}_{2}$ peak: Maximal oxygen consumption $\left(\mathrm{mL}^{\mathrm{kg}}{ }^{-1} \cdot \mathrm{min}^{-1}\right)$; WES: Whole exome sequencing

\section{Acknowledgements}

We appreciate the assistance of Ariane Levesque (McGill University) for her review of the article in the English language.

\section{Funding}

This work is supported by the Institute of Cancer Research (ICR) of the Canadian Institutes of Health Research (CIHR), in collaboration with C17 Council, Canadian Cancer Society (CCS), Cancer Research Society (CRS), Garron Family Cancer Centre at the Hospital for Sick Children, Ontario Institute for Cancer Research (OICR) and Pediatric Oncology Group of Ontario (POGO) (grant number: TCF 118694). This research is also supported in part by PhD study grants from Cole Foundation, Fonds de Recherche du Québec - Santé (FRQS), Sainte-Justine University Hospital Center Foundation and Foundation of Stars. The funding body had no role in the design of the study, collection, analysis, interpretation of data, or in writing the manuscript. Also, there are no companies or manufacturers that will benefit from the results of this study.

\section{Availability of data and materials}

Our data are not deposited in publicly available repositories. However, the datasets used and/or analyzed during the current study are available from the corresponding author on reasonable request.

\section{Authors' contributions}

$M C, D S, M K, G A, C L, L B, S D$ and $D C$ conceived the study and participated in the design and coordination. VL performed cardiopulmonary exercise tests. $\mathrm{VL}$ and $\mathrm{MC}$ collected the cardiorespiratory data and classified participants according to their cardiorespiratory fitness level. PSO and PB performed the acquisition and processed the genetic data of the PETALE survivors. MC and KP did the genetic association studies and MC interpreted the data. MC, SD, MK, DS and DC contributed to the writing of the manuscript. All authors have read and approved this manuscript.

\section{Ethics approval and consent to participate}

Written informed consent was obtained from every patient or parent/legal guardian. The study was conducted in accordance with the Declaration of Helsinki and the protocol was approved by the Ethics Review Committee of Sainte-Justine University Health Center.

\section{Consent for publication}

Not applicable.

Competing interests

The authors declare that they have no competing interests.

\section{Publisher's Note}

Springer Nature remains neutral with regard to jurisdictional claims in published maps and institutional affiliations.

\section{Author details}

'Laboratoire de Physiopathologie de l'EXercice (LPEX), École de Kinésiologie et des Sciences de l'Activité physique, Faculté de Médecine, Université de Montréal, CEPSUM, 2100, boulevard Édouard Montpetit, Montréal, QC H3C 3J7, Canada. ${ }^{2}$ Department of psychology, Laboratoire EA 4430 - Clinique Psychanalyse Developpement (CliPsyD), University of Paris Nanterre, Nanterre, Ile-de-France, France. ${ }^{3}$ Research Center, Sainte-Justine University Health Center, Montreal, Quebec, Canada. ${ }^{4}$ Department of pharmacology and physiology, University of Montreal, Montreal, Quebec, Canada. ${ }^{5}$ Department of Pediatrics, University of Montreal, Montreal, Quebec, Canada. 


\section{Received: 11 July 2018 Accepted: 29 April 2019} Published online: 14 May 2019

\section{References}

1. Brenner H, Kaatsch P, Burkhardt-Hammer T, Harms DO, Schrappe M, Michaelis J. Long-term survival of children with leukemia achieved by the end of the second millennium. Cancer. 2001;92(7):1977-83.

2. Van Brussel M, Takken T, Lucia A, van der Net J, Helders PJ. Is physical fitness decreased in survivors of childhood leukemia? A systematic review. Leukemia. 2005;19(1):13-7.

3. Courneya KS. Exercise in cancer survivors: an overview of research. Med Sc Sports Exerc. 2003;35(11):1846-52.

4. Speck RM, Courneya KS, Masse LC, Duval S, Schmitz KH. An update of controlled physical activity trials in cancer survivors: a systematic review and meta-analysis. J Cancer Surviv Res Pract. 2010;4(2):87-100.

5. Spence RR, Heesch KC, Brown WJ. Exercise and cancer rehabilitation: a systematic review. Cancer Treat Rev. 2010;36(2):185-94.

6. Wurz A, Brunet J. The effects of physical activity on health and quality of life in adolescent Cancer survivors: a systematic review. JMIR cancer. 2016;24; 2(1):e6.

7. Bouchard C, Blair SN, Church TS, Earnest CP, Hagberg JM, Hakkinen K, Jenkins NT, Karavirta L, Kraus WE, Leon AS, et al. Adverse metabolic response to regular exercise: is it a rare or common occurrence? PLoS One. 2012;7(5):e37887

8. Chomistek AK, Chasman DI, Cook NR, Rimm EB, Lee IM. Physical activity, genes for physical fitness, and risk of coronary heart disease. Med Sci Sports Exerc. 2013;45(4):691-7

9. Norman B, Esbjornsson M, Rundqvist H, Osterlund T, Glenmark B, Jansson E. ACTN3 genotype and modulation of skeletal muscle response to exercise in human subjects. J Appl Physiol(Bethesda, Md: 1985). 2014;116(9):1197-203.

10. Niemi AK, Majamaa K. Mitochondrial DNA and ACTN3 genotypes in Finnish elite endurance and sprint athletes. Eur J Hum Genet: EJHG. 2005:13(8):965-9.

11. Rico-Sanz J, Rankinen T, Joanisse DR, Leon AS, Skinner JS, Wilmore JH, Rao DC, Bouchard C. Associations between cardiorespiratory responses to exercise and the C34T AMPD1 gene polymorphism in the HERITAGE family study. Physiol Genomics. 2003;14(2):161-6.

12. Gniazdowski M, Denny WA, Nelson SM, Czyz M. Effects of anticancer drugs on transcription factor-DNA interactions. Expert Opin Ther Targets. 2005;9(3): 471-89.

13. Senkus $E$, Jassem J. Cardiovascular effects of systemic cancer treatment. Cancer Treat Rev. 2011:37(4):300-11.

14. Silverman LB, Stevenson KE, O'Brien JE, Asselin BL, Barr RD, Clavell L, Cole PD, Kelly KM, Laverdiere C, Michon B, et al. Long-term results of Dana-Farber Cancer Institute ALL consortium protocols for children with newly diagnosed acute lymphoblastic leukemia (1985-2000). Leukemia. 2010;24(2): 320-34.

15. Marcoux S, Drouin S, Laverdiere C, Alos N, Andelfinger GU, Bertout L, Curnier D, Friedrich MG, Kritikou EA, Lefebvre G, et al. The PETALE study: late adverse effects and biomarkers in childhood acute lymphoblastic leukemia survivors. Pediatr Blood Cancer. 2017:64(6):1-8.

16. Bar-Or O, Rowland TW. Pediatric exercise medicine: from physiologic principles to health care application. Champaign: Human Kinetics; 2004

17. Guazzi M, Adams V, Conraads V, Halle M, Mezzani A, Vanhees L, Arena $R$, Fletcher GF, Forman DE, Kitzman DW, et al. EACPR/AHA scientific statement. Clinical recommendations for cardiopulmonary exercise testing data assessment in specific patient populations. Circulation. 2012;126(18):2261-74

18. Hansen JE, Sue DY, Wasserman K. Predicted values for clinical exercise testing. Am Rev Respir Dis. 1984;129(2 Pt 2):S49-55.

19. Wasserman K, Hansen JE, Sue DY, Stringer W, Whipp BJ: Principles of exercise testing and interpretation. In: Normal Values 4th, edn. Edited by Weinberg R. Philadelphia, PA: Lippincott Williams and Wilkins; 2005 160-182.

20. Cooper DM, Weiler-Ravell D, Whipp BJ, Wasserman K. Growth-related changes in oxygen uptake and heart rate during progressive exercise in children. Pediatr Res. 1984;18(9):845-51.

21. de Onis M, Onyango AW, Borghi E, Siyam A, Nishida C, Siekmann J. Development of a WHO growth reference for school-aged children and adolescents. Bull World Health Organ. 2007:85(9):660-7.

22. GITHUB-PICARD [http://broadinstitute.github.io/picard]. Accessed June 2018.
23. McKenna A, Hanna M, Banks E, Sivachenko A, Cibulskis K, Kernytsky A, Garimella K, Altshuler D, Gabriel S, Daly M, et al. The genome analysis Toolkit: a MapReduce framework for analyzing next-generation DNA sequencing data. Genome Res. 2010;20(9):1297-303.

24. Li H, Handsaker B, Wysoker A, Fennell T, Ruan J, Homer N, Marth G, Abecasis $\mathrm{G}$, Durbin R. The sequence alignment/map format and SAMt ools. Bioinf (Oxford, England). 2009;25(16):2078-9.

25. Wang K, Li M, Hakonarson H. ANNOVAR: functional annotation of genetic variants from high-throughput sequencing data. Nucleic Acids Res. 2010; 38(16):e164.

26. Kumar P, Henikoff S, Ng PC. Predicting the effects of coding nonsynonymous variants on protein function using the SIFT algorithm. Nat Protoc. 2009:4(7):1073-81.

27. Adzhubei I, Jordan DM, Sunyaev SR: Predicting functional effect of human missense mutations using PolyPhen-2. Current protocols in human genetics 2013, Chapter 7:Unit7.20

28. Abecasis GR, Altshuler D, Auton A, Brooks LD, Durbin RM, Gibbs RA, Hurles $\mathrm{ME}, \mathrm{McV}$ ean GA. A map of human genome variation from population-scale sequencing. Nature. 2010;467(7319):1061-73.

29. NHLBI GO Exome Sequencing Project (ESP) [http://evs.gs.washington.edu/ EVS/].

30. Morrison J, Gauderman W. Quanto, 1.2.4 edn. Los Angeles, CA: USC University of Southern California; 2009.

31. Bray MS, Hagberg JM, Perusse L, Rankinen T, Roth SM, Wolfarth B, Bouchard $C$. The human gene map for performance and health-related fitness phenotypes: the 2006-2007 update. Med Sci Sports Exerc. 2009; 41(1):35-73.

32. Williams CJ, Williams MG, Eynon N, Ashton KJ, Little JP, Wisloff U, Coombes JS. Genes to predict VO(2max) trainability: a systematic review. BMC Genomics. 2017;18(Suppl 8):831:82-110

33. Sarzynski MA, Loos RJ, Lucia A, Perusse L, Roth SM, Wolfarth B, Rankinen T, Bouchard C. Advances in exercise, fitness, and performance genomics in 2015. Med Sci Sports Exerc. 2016;48(10):1906-16

34. Eden E, Navon R, Steinfeld I, Lipson D, Yakhini Z. GOrilla: a tool for discovery and visualization of enriched $\mathrm{GO}$ terms in ranked gene lists. BMC Bioinf. 2009;10(1):48.

35. Purcell S, Neale B, Todd-Brown K, Thomas L, Ferreira MA, Bender D, Maller J, Sklar P, de Bakker PI, Daly MJ, et al. PLINK: a tool set for whole-genome association and population-based linkage analyses. Am J Hum Genet. 2007; 81(3):559-75.

36. Benjamini $Y$, Hochberg $Y$. Controlling the false discovery rate: a practical and powerful approach to multiple testing. J R Stat Soc Ser B Methodol. 1995;7(1):289-300.

37. Team R. RStudio: integrated development for R. Boston URL http://www. rstudio.com: RStudio, Inc; 2017.

38. England J, Drouin S, Beaulieu P, St-Onge P, Krajinovic M, Laverdière C, Levy E, Marcil V, Sinnett D. Genomic determinants of long-term cardiometabolic complications in childhood acute lymphoblastic leukemia survivors. BMC Cancer. 2017:17:1-14.

39. Wu MC, Lee S, Cai T, Li Y, Boehnke M, Lin X. Rare-variant association testing for sequencing data with the sequence kernel association test. Am J Hum Genet. 2011;89(1):82-93.

40. Storey JD, Taylor JE, Siegmund D. Strong control, conservative point estimation and simultaneous conservative consistency of false discovery rates: a unified approach. J R Stat Soc Ser B Stat Methodol. 2004;66(1): 187-205.

41. Storey JD. A direct approach to false discovery rates. J R Stat Soc Ser B Stat Methodol. 2002;64(3):479-98.

42. IBM Corp. In: IBM Corp, editor. Released IBM SPSS Statistics for Macintosh. 24.0 ed. Armonk; 2013

43. Vikhlyantsev IM, Podlubnaya ZA. New titin (connectin) isoforms and their functional role in striated muscles of mammals: facts and suppositions. Biochemistry Biokhimiia. 2012;77(13):1515-35.

44. Hackman P, Vihola A, Haravuori H, Marchand S, Sarparanta J, De Seze J, Labeit S, Witt C, Peltonen L, Richard I, et al. Tibial muscular dystrophy is a titinopathy caused by mutations in TTN, the gene encoding the giant skeletal-muscle protein titin. Am J Hum Genet. 2002;71(3):492-500.

45. Rankinen T, Rice T, Boudreau A, Leon AS, Skinner JS, Wilmore JH, Rao DC, Bouchard C. Titin is a candidate gene for stroke volume response to endurance training: the HERITAGE family study. Physiol Genomics. 2003; 15(1):27-33 
46. Bailleul B, Akerblom I, Strosberg AD. The leptin receptor promoter controls expression of a second distinct protein. Nucleic Acids Res. 1997;25(14):2752-8.

47. Chiu KC, Chu A, Chuang LM, Saad MF. Association of leptin receptor polymorphism with insulin resistance. Eur J Endocrinol. 2004;150(5):725-9.

48. Soeters MR, Soeters PB. The evolutionary benefit of insulin resistance. Clin Nutr(Edinburgh, Scotland). 2012;31(6):1002-7.

49. Rico-Sanz J, Rankinen T, Rice T, Leon AS, Skinner JS, Wilmore JH, Rao DC, Bouchard C. Quantitative trait loci for maximal exercise capacity phenotypes and their responses to training in the HERITAGE family study. Physiol Genomics. 2004;16(2):256-60.

50. Stefan N, Vozarova B, Del Parigi A, Ossowski V, Thompson D, Hanson R, Ravussin E, Tataranni P. The GIn223Arg polymorphism of the leptin receptor in Pima Indians: influence on energy expenditure, physical activity and lipid metabolism. Int J Obes. 2002;26(12):1629.

51. Hwa V, Oh Y, Rosenfeld RG. The insulin-like growth factor-binding protein (IGFBP) superfamily. Endocr Rev. 1999;20(6):761-87.

52. Hasani-Ranjbar S, Soleymani Far E, Heshmat R, Rajabi H, Kosari H. Time course responses of serum GH, insulin, IGF-1, IGFBP1, and IGFBP3 concentrations after heavy resistance exercise in trained and untrained men. Endocrine. 2012:41(1):144-51.

53. Lavoie JM, Fillion Y, Couturier K, Corriveau P. Evidence that the decrease in liver glycogen is associated with the exercise-induced increase in IGFBP-1. J Appl Physiol (Bethesda, Md : 1985). 2002;93(2):798-804; discussion 797.

54. Simonen RL, Rankinen T, Perusse L, Rice T, Rao DC, Chagnon Y, Bouchard C. Genome-wide linkage scan for physical activity levels in the Quebec family study. Med Sci Sports Exerc. 2003;35(8):1355-9.

55. Comi GP, Fortunato F, Lucchiari S, Bordoni A, Prelle A, Jann S, Keller A, Ciscato P, Galbiati S, Chiveri L. $\beta$-Enolase deficiency, a new metabolic myopathy of distal glycolysis. Ann Neurol. 2001;50(2):202-7.

56. Peshavaria M, Day IN. Molecular structure of the human muscle-specific enolase gene (ENO3). Biochem J. 1991;275(Pt 2):427-33.

57. Giallongo A, Venturella S, Oliva D, Barbieri G, Rubino P, Feo S. Structural features of the human gene for muscle-specific enolase. FEBS J. 1993;214(2): 367-74

58. Chen SH, Giblett ER. Enolase: human tissue distribution and evidence for three different loci. Ann Hum Genet. 1976;39(3):277-80.

59. Newsholme E. Regulation of carbohydrate metabolism in muscle: identification of regulatory enzymes. Regulation in metabolism. London: Wiley; 1973. p. 103

60. Tonorezos ES, Snell PG, Moskowitz CS, Eshelman-Kent DA, Liu JE, Chou JF, Smith SM, Dunn AL, Church TS, Oeffinger KC. Reduced cardiorespiratory fitness in adult survivors of childhood acute lymphoblastic leukemia. Pediatr Blood Cancer. 2013;60(8):1358-64.

61. Lipshultz SE, Colan SD, Gelber RD, Perez-Atayde AR, Sallan SE, Sanders SP. Late cardiac effects of doxorubicin therapy for acute lymphoblastic leukemia in childhood. N Engl J Med. 1991;324(12):808-15.

62. Hovi L, Era P, Rautonen J, Siimes MA. Impaired muscle strength in female adolescents and young adults surviving leukemia in childhood. Cancer. 1993;72(1):276-81.

63. Warner JT, Bell W, Webb DK, Gregory JW. Relationship between cardiopulmonary response to exercise and adiposity in survivors of childhood malignancy. Arch Dis Child. 1997;76(4):298-303.

64. Rajic V, Aplenc R, Debeljak M, Prestor W, Karas-Kuzelicki N, Mlinaric-Rascan I, Jazbec J. Influence of the polymorphism in candidate genes on late cardiac damage in patients treated due to acute leukemia in childhood. Leuk Lymphoma. 2009;50(10):1693-8.

65. Thorn CF, Oshiro C, Marsh S, Hernandez-Boussard T, McLeod H, Klein TE, Altman RB. Doxorubicin pathways: pharmacodynamics and adverse effects. Pharmacogenet Genomics. 2011;21(7):440-6.

66. Visscher H, Ross CJ, Rassekh SR, Barhdadi A, Dube MP, Al-Saloos H, Sandor GS, Caron HN, van Dalen EC, Kremer LC, et al. Pharmacogenomic prediction of anthracycline-induced cardiotoxicity in children. J Clin Oncol Off J Am Soc Clin Oncol. 2012:30(13):1422-8.

67. Harake D, Franco VI, Henkel JM, Miller TL, Lipshultz SE. Cardiotoxicity in childhood cancer survivors: strategies for prevention and management. Futur Cardiol. 2012;8(4). https://doi.org/10.2217/fca.2212.2244.

68. Lakoski SG, Eves ND, Douglas PS, Jones LW. Exercise rehabilitation in patients with cancer. Nat Rev Clin Oncol. 2012;9(5):288-96.

69. Lipshultz SE, Lipsitz SR, Sallan SE, Dalton VM, Mone SM, Gelber RD, Colan SD. Chronic progressive cardiac dysfunction years after doxorubicin therapy for childhood acute lymphoblastic leukemia. J Clin Oncol Off J Am Soc Clin Oncol. 2005:23(12):2629-36.

70. Johnson D, Perrault $H$, Fournier A, Leclerc JM, Bigras JL, Davignon A. Cardiovascular responses to dynamic submaximal exercise in children previously treated with anthracycline. Am Heart J. 1997;133(2):169-73.

71. Plana JC, Galderisi M, Barac A, Ewer MS, Ky B, Scherrer-Crosbie M, Ganame J, Sebag IA, Agler DA, Badano LP, et al. Expert consensus for multimodality imaging evaluation of adult patients during and after cancer therapy: a report from the American Society of Echocardiography and the European Association of Cardiovascular Imaging. J Am Soc Echocardiogr. 2014;27(9): 911-39.

72. Lal S, Wong ZW, Jada SR, Xiang X, Chen Shu X, Ang PC, Figg WD, Lee EJ, Chowbay B. Novel SLC22A16 polymorphisms and influence on doxorubicin pharmacokinetics in Asian breast cancer patients. Pharmacogenomics. 2007; 8(6):567-75.

73. Brass EP. Supplemental carnitine and exercise. Am J Clin Nutr. 2000;72(2): 618S-23S.

74. Wall BT, Stephens FB, Constantin-Teodosiu D, Marimuthu K, Macdonald IA Greenhaff PL. Chronic oral ingestion of I-carnitine and carbohydrate increases muscle carnitine content and alters muscle fuel metabolism during exercise in humans. J Physiol. 2011;589(4):963-73.

75. Vecchiet L, Di Lisa F, Pieralisi G, Ripari P, Menabo R, Giamberardino M, Siliprandi N. Influence of L-carnitine administration on maximal physical exercise. Eur J Appl Physiol Occup Physiol. 1990;61(5-6):486-90.

76. Gorostiaga EM, Maurer CA, Eclache JP. Decrease in respiratory quotient during exercise following L-carnitine supplementation. Int J Sports Med. 1989;10(3):169-74.

77. Marconi C, Sassi G, Carpinelli A, Cerretelli P. Effects ofl-carnitine loading on the aerobic and anaerobic performance of endurance athletes. Eur J Appl Physiol Occup Physiol. 1985;54(2):131-5

78. Faraji A, Dehghan Manshadi HR, Mobaraki M, Zare M, Houshmand M. Association of ABCB1 and SLC22A16 gene polymorphisms with incidence of doxorubicin-induced febrile neutropenia: a survey of Iranian breast Cancer patients. PLoS One. 2016;11(12):e0168519.

79. Krajinovic M, Labuda D, Richer C, Karimi S, Sinnett D. Susceptibility to childhood acute lymphoblastic leukemia: influence of CYP1A1, CYP2D6, GSTM1, and GSTT1 genetic polymorphisms. Blood. 1999;93(5):1496-501.

\section{Ready to submit your research? Choose BMC and benefit from:}

- fast, convenient online submission

- thorough peer review by experienced researchers in your field

- rapid publication on acceptance

- support for research data, including large and complex data types

- gold Open Access which fosters wider collaboration and increased citations

- maximum visibility for your research: over $100 \mathrm{M}$ website views per year

At $\mathrm{BMC}$, research is always in progress.

Learn more biomedcentral.com/submission 